\title{
DA DEMOCRACIA DOS PARTIDOS AO PLEBISCITO DA AUDIENCE*
}

\author{
Nadia Urbinati
}

Nesta breve contribuição, gostaria de defender uma tese forte e provavelmente controversa: na democracia contemporânea (em alguns países mais do que em outros), os partidos políticos, atores essenciais do sistema representativo desde seu surgimento na Inglaterra dos commonwealthmen ${ }^{1}$, mudaram sua função, mas não perderam importância ou acabaram, como frequentemente se ouve dizer; a esta mudança deles correspondeu uma transformação da democracia de representativa em plebiscitária, com o esclarecimento de que o plebiscitarismo contemporâneo não é feito de massas mobilizadas por líderes carismáticos conforme

\footnotetext{
* Tradução de Carlo Alberto Dastoli.

${ }^{1}$ Em $A$ dissertation upon parties, por ele publicado em fascículos semanais entre 1733 e 1734 na revista política The Crafstman, Henry St. John Bolingbroke justificava pela primeira vez na Europa moderna a "divisão" partidária como positiva no governo baseado nas eleições, desde que nenhum partido questionasse a constituição ou usasse o governo para perseguir interesses particulares. Divisão partidária era uma divisão de interpretação política sobre o comportamento do governo existente com o objetivo de promover um governo diferente. Sobre a formação dos partidos juntamente com a transformação da designação dos encargos para eleição na Inglaterra do século XVII, ver Kishlansky (1986).
} 
quer Max Weber e teorizado por Carl Schmitt como forma mais completa de democracia. $\mathrm{O}$ novo plebiscitarismo é o da audience, o aglomerado indistinto de indivíduos que compõe o público, um ator não coletivo que vive no espaço privado da domesticidade e, quando é agente sondado de opinião, atua como receptor ou espectador de um espetáculo encenado por técnicos da comunicação midiática e recitado por personagens políticos ${ }^{2}$. A personalização do poder e da política é um sintoma e um sinal tanto da transformação dos partidos quanto da formação da democracia da audience $e^{3}$. Sobre a transformação dos partidos, um ponto sobre o qual, aliás, não pretendo concentrar minha atenção, ela diz respeito ao seu emagrecimento democrático, ao qual corresponde uma obesidade de poder material efetivo nas instituições do Estado e, sobretudo, à série de funções que se desenvolve pelo Executivo, o poder do Estado que essa transformação exaltou além e acima do poder do Par86 lamento ${ }^{4}$. Por esse motivo, não é convincente apresentar a democracia de partidos como uma fase, agora passada, da história do governo representativo ${ }^{5}$. É verdade que, para todos os efeitos, ela se tornou uma democracia "dos" partidos, ou seja, exercida por eles sem mais buscar (ainda antes de ter) uma relação com os cidadãos que não seja estrategicamente orientada para a conquista dos votos: democracia “dos" em vez de "por meio dos" partidos. O declínio dos partidos é, portanto, declínio de uma forma democrática de ser do partido político; um declínio que se manifesta com a restrição até o desaparecimento de sua estrutura organizati-

\footnotetext{
${ }^{2}$ Sobre o recrutamento por parte dos partidos de especialistas de comunicação e produtores televisivos, ver Fabbrini (1998, p. 36).

${ }^{3}$ Um dos primeiros na Itália a identificar os sinais da personalização do poder e da transformação plebiscitária foi Cavalli (1981).

${ }^{4}$ Sobre a estreita relação entre transformação dos partidos e fortalecimento do Executivo - muito visível não apenas nos Estados Unidos, mas também na Inglaterra, berço e fortaleza do parlamentarismo, ver Poguntke e Webb (2005).

${ }^{5}$ Esta é a tese defendida por Manin (1997).
} 
va periférica ou territorial, sinal tangível de uma transformação de função, uma vez que a organização (partido pesado) é adequada para um partido que deve buscar uma relação muito estreita e continuada (não apenas no momento das eleições) com os cidadãos, para mobilizá-los ou torná-los partícipes (em favor de um partido) por meio de narrativas ideológicas que criam identidades de pertencimento ou de inspiração ideal e servem de instrumentos interpretativos e críticos ${ }^{6}$; o partido como estrutura articulada da base ao topo e vice-versa, que regula a designação coletiva e por consenso dos líderes locais e nacionais, que constitui um ator coletivo público. A erosão do partido-organização não significou o fim do partido, mas o fim de um partido que precisava buscar e buscava inserção na sociedade porque aspirava a construir um consenso e a obter uma afirmação que não era apenas numérica, mas era também de projeto. Aquele partido pesado por se fundamentar na organização, estava metade dentro e metade fora das instituições estatais, ponto de articulação entre Estado e sociedade, um "corpo intermediário" da democracia representativa que desempenhava várias funções de limitação do poder: escolha dos candidatos, controle dos eleitos (que o mandato livre torna legalmente irresponsáveis perante os cidadãos), estímulo e orientação da opinião; enfim, ele servia de verdadeira escola para a formação do pessoal político das instituições periféricas e centrais do Estado ${ }^{7}$. Nas primeiras décadas do segundo pós-guerra, época da formação e da consolidação da democracia representativa na Europa, a democracia dos partidos

\footnotetext{
${ }^{6}$ Michael Freeden explicou como a ideologia é uma maneira de simplificar uma realidade social complexa cujo núcleo de significado, de outro modo, fugiria à compreensão de muitos. Simplificando a complexidade, a ideologia é um guia prático para "a conversão da inevitável variedade das opiniões em uma certeza monolítica que é a inevitável forma de uma decisão política e está na base da construção de uma identidade política" (Freeden, 1996, pp. 76-7).

${ }^{7}$ Remeto ao capítulo 1 de Urbinati (2006). Sobre a função da organização no partido político, ver, entre outros, Mair (1994).
} 
dirigiu o recrutamento entre cidadãos/cidadãs comuns de prefeitos e dirigentes, de parlamentares e ministros.

O declínio dessa forma de partido correspondeu ao crescimento proporcional do partido eleitoralista, dedicado exclusivamente à reprodução de si mesmo como organismo interno às instituições, ou seja, à reprodução da classe política; uma função muito mais semelhante da anterior àquela forma oligárquica cujo surgimento havia sido diagnosticado por Robert Michels e Vilfredo Pareto. Os partidos da democracia "dos" partidos encontram-se bem-instalados na estrutura do Estado e longe de estar em declínio; estão encerrados no Estado e são capazes de fortalecer "a própria capacidade de controle dos acessos ao poder institucional, contando com o fato ou a ilusão de que, a longo prazo, terão nas próprias mãos o monopólio do governo" (Calise, 2010, p. 45). Isso não significa que eles gozem de legitimidade moral entre os cidadãos; 88 nunca como hoje estão destituídos de legitimidade. Significa, ao contrário, que para todos os efeitos se tornaram um meio indispensável para poder perseguir uma carreira (cada vez mais privilegiada precisamente por ser cada vez menos democrática) e que têm como principal referência as instituições do Estado em todas suas ramificações, do nível ministerial ao regional, frequentemente impermeáveis à voz dos cidadãos.

Nos partidos tradicionais, os militantes desempenhavam o papel crucial de 'terminais inteligentes' das demandas provenientes dos vários segmentos da sociedade [...], constituíam um sistema capilar e difuso de levantamento das preferências do eleitorado, fornecendo à organização de partido e a seus dirigentes as informações necessárias para fazer as escolhas em uma ou em outra direção (Calise, 2010, p. 43). 
Com os novos partidos líquidos ou leves, a função de captar interesses e opiniões, uma função de representatividade, é desempenhada não mais pelas ideias e pelos relatos ideológicos, mas pelas sondagens. Desse modo, as sondagens servem ao partido não para representar melhor ou mesmo para direcionar a política governamental, mas para vencer as eleições e acompanhar melhor os humores sociais. O declínio do partido-organização correspondeu ao crescimento de um partido-esponja, ou seja, que segue os fluxos e de alguma maneira os irriga ou alimenta habilmente para melhor obter consenso. Enfim, o partido leve é de difícil controle por parte dos cidadãos simpatizantes e inscritos que não dispõem mais de estruturas e regras para a articulação interna das divergências e do domínio, enquanto está propenso a exaltar a pessoa do líder e, por isso, pode passar a incentivar políticas populistas, se considera isso conveniente, em vez de ser um dique que as contém como era o partido-organização. Esse desvio de organização para liquididade e profissionalização sondagística, de educador político para seguidor e instigador dos humores populares faz com que a democracia "dos" partidos seja uma democracia voltada para novas formas plebiscitárias. Este é o aspecto sobre o qual gostaria de me deter aqui.

\section{A democracia do público}

A democracia do público, aquela que chamo plebiscitarismo da audience, é o resultado não do fim da democracia “dos" partidos, mas da afirmação deles como corpo oligárquico que deixa de ser intermediário para se tornar ocupante direto e por seu próprio interesse da política representada. Esse argumento quer ser uma resposta ao proposto por Bernard Manin (1997). A posição de Manin toma como base e desenvolve a crítica de Carl Schmitt à democracia parlamentarista da qual partiu a teoria da democracia ple- 
biscitária. Schmitt interpretou a democracia plebiscitária insistindo na mudança de significado do "público" de uma categoria jurídico-normativa (aquilo que pertence ao estado civil) para uma categoria estética, como algo que está exposto à visão e existe em sentido teatral (aquilo que é feito diante dos olhos do povo).

Essa visão romana do público - com a centralidade do fórum - retorna no plebiscitarismo contemporâneo, como demonstram os recentes escritos de Jeffrey Edward Green e depois de Eric C. Posner e Adrian Vermeule (que retomam e desenvolvem o conceito de Manin) (Green, 2010; Posner e Vermeule, 2011). O ressurgimento dos argumentos e das ideias que guiaram a crise do parlamentarismo nas primeiras décadas do século XX - quando a concepção plebiscitária assumiu uma configuração alternativa à democracia representativa ou dos partidos - é uma indicação preocupante da nova linha de pesquisa teórica e aplicação prática 90 interna à democracia contemporânea, uma linha mais uma vez crítica em relação à estrutura parlamentar e à função mediadora dos partidos políticos. Manin (1997) talvez seja o documento que melhor representa essa tendência, se não por outras coisas, por captar a transformação e até teorizá-la como sinal de uma mudança em sentido mais democrático - quando por democracia Manin entende democracia de massa guiada por líderes, como na formulação de Weber e Schmitt. O tema conclusivo de Manin (1997) é o diagnóstico do declínio da democracia do partido político e o crescimento da democracia do público na qual a confiança no líder e a aceitação de uma crescente exigência de poder discricionário por parte do Executivo se encontram com uma mudança na organização da democracia eleitoral que agora é dirigida não mais por partidos de líderes e de militantes, mas por partidos de especialistas da comunicação e de candidatos à carreira política. "A democracia da audience é governo dos especialistas da mídia” (Manin, 1997, p. 221) 
e, portanto, a celebração do "poder ocular", como escreve Green completando o diagnóstico de Manin. Enquanto na época da democracia dos partidos políticos as eleições eram fortemente baseadas na dimensão vocal e no aspecto volitivo da política - a participação na decisão era expressão da forma clássica da soberania popular que os partidos se encarregavam de organizar -, a aparição em público ou a submissão ao veredicto da audience é agora aquilo que define a arte da política.

A transição da centralidade da vontade para a centralidade da opinião é um corolário dessa transformação. De fato, a voz é o órgão de uma ação política que deseja ser de proposta e de crítica, expressão de uma ideia de participação ativa ou inclinada à decisão segundo a definição clássica da soberania democrática como autonomia ou autogoverno, ou seja, de criação de leis. Por outro lado, a visão é o órgão de uma ação julgadora não atuante, que avalia alguma coisa que existe, que outros fazem e que se mostra ao olhar de quem está habilitado mais a julgar que a agir. Palavras, discussões e conflitos entre ideias e interesses (ou entre programas de partidos), ou seja, deliberação em sentido lato, são centrais quando a voz é o centro da política; transparência ou "candura" (no sentido romano clássico pelo qual quem se candidatava vestia uma estola cândida dando assim o sinal de desejar expor-se ao público) são centrais no caso da democracia da audience, em que o órgão do poder popular se torna "mais a observação que a decisão, e o ideal crítico do poder do povo é mais a candura que a autonomia" (Green, 2010, p. 15).

A democracia da audience constitui um passo significativo para a política da passividade espectatorial. Como escreveu Pierre Rosanvallon diagnosticando o incremento do poder "negativo" contra o "propositivo" nas democracias contemporâneas, a legitimidade informal que a ação de contrademocracia gera não consiste em instar as insti- 
tuições do ponto de vista da vontade popular (é o sufrágio que confere esta legitimidade), mas em manter as instituições sob os holofotes, se assim se pode dizer, sob os olhos de um público que deseja olhar. Nas democracias contemporâneas, os cidadãos não perseguem mais a democracia representativa em nome da democracia direta ou de mais participação, mas a criticam em nome da política representada, ou seja, literalmente exposta ao público. Em vez do povo-eleitor, a legitimidade informal da contrademocracia tem como protagonista o povo-juiz ou controlador, o olhar público que quer ver, não a voz que reivindica a ação. $\mathrm{O}$ poder julgador é um poder negativo ou censório.

A história das formas de poder negativo é longa e rica. Vai do tribunado e do eforado à petição ao monarca e à denúncia pela imprensa; ao monitoramento por meio de associações da sociedade civil; à contestação por meio dos movimentos sociais, dos partidos políticos e agora também

92 à ação da Internet. E ainda: às formas jurídicas de impedimento como a do Supremo Tribunal norte-americano ou as dos tribunais constitucionais em nossos ordenamentos parlamentares; às formas de ação judiciária individual e coletiva contra as decisões políticas e administrativas do Estado, enfim, às moderníssimas formas de oposição realizadas pelos movimentos antiglobalização, ao poder das agências internacionais como a ONU de interferir na ação dos governos monitorando-os em vista da defesa dos direitos humanos, mas também ao poder bem mais penetrante do mercado - talvez o poder negativo moderno mais influente precisamente pela capacidade que teve até aqui de reivindicar a legitimidade, de impor vetos às decisões políticas em nome de regras pretensamente neutras e até naturais, regras impessoais e totalmente indiretas ${ }^{8}$. Das três formas de poder negativo - a de impedimento, a de vigilância e a de julga-

\footnotetext{
${ }^{8}$ Essa tese está no centro de Rosanvallon (2006).
} 
mento -, a última é sem dúvida a mais moderna e a que teve um crescimento extraordinário na segunda metade do século XX, quer em consequência da vitória judiciária com a qual se concluiu a Segunda Guerra Mundial (um fato extraordinário que levou o julgamento a desenvolver um papel absolutamente inédito de legitimação por meio da razão de uma "vitória" experimentada no campo de batalha) e depois em relação à inovação tecnológica dos meios de informação e ao crescimento da sociedade civil, nacional e global.

Convém esclarecer que o julgamento como forma de ação política cria uma série de problemas para as estratégias clássicas de oposição e de denúncia e não deve ser concebido como substitutivo da decisão política democrática. Antes de tudo porque ele aumenta o poder dos processos jurídicos e dos juízes (sejam eles os da opinião midiática, dos mercados acionários, sejam os que encontram assento nos tribunais), um poder que tende a deprimir o dos corpos políticos, como é o caso dos partidos-organização, mas também dos parlamentos e dos cidadãos eleitores. Em segundo lugar, enquanto a decisão política - mesmo quando é transformada em objeto de contestação - mobiliza o cidadão ativo, a ação julgadora dá destaque ao papel do "espectador" e envolve um critério de julgamento, o da imparcialidade, que é externo à política. Em terceiro lugar, a ação do julgamento amplia a dimensão pública, mas em uma forma que é de teatralidade ou estética e que por isso se presta a ser instrumentalizada pelos meios de comunicação de massa, os quais tendem a transformar o processo de formação das opiniões em uma espécie de tribunal da transparência e da revelação que condiz mais com a demagogia que com a deliberação pensada ${ }^{9}$.

Voltando a Manin, ao concluir a análise histórica das formas do governo representativo, ele afirma que, em

\footnotetext{
${ }^{9}$ Abordei esses temas em Urbanati (2010). Ver também Pizzorno (1998).
} 
comparação com a democracia dirigida pelos partidos, a democracia pós-partidária ou "do público" prefigura uma ampliação da liberdade porque "a ascensão dos meios de comunicação de massa e não de partido determina uma consequência importante: sejam quais forem suas preferências, todos os indivíduos recebem as mesmas informações sobre determinado assunto. As pessoas, obviamente, continuam a ter opiniões divergentes sobre as questões políticas, mas a própria percepção do tema tende a se emancipar das tendências políticas individuais" (Manin, 1997, pp. 2289). Esse corolário vale desde que os meios de informação sejam públicos ou não sujeitos ao monopólio de capitais privados ou de maiorias parlamentares. Nessas condições, a democracia da audience, de acordo com Manin, seria mais democrática porque colocaria a todos indistintamente na condição de receber as informações sem comprometimento ideológico ou partidário.

94 No entanto, a "democracia do público" oferece uma imagem bem diferente, mesmo quando as fontes de informação são públicas e mesmo quando, embora privadas, não são monopolizadas por quem aspira à liderança política: a de uma reestruturação e de uma reorganização da forma partido com base em objetivos e critérios que não são necessariamente mais democráticos. Na Itália, país em que o telepopulismo lançou um desafio radical ao sistema de partidos tradicionais, Silvio Berlusconi conseguiu conquistar uma maioria estável apenas quando criou seu próprio partido, promovendo uma forte identidade ideológica (até mais marcada que a dos velhos partidos) e dando a seus eleitores a certeza de pertencer a um partido, não apenas a uma televisão comercial. Se à primeira vista a "democracia do público" parece encarnar um sistema de representação fluido, aberto, caracterizado pela indeterminação e dirigido por candidatos individuais e não pelos membros homologados de partidos-organização, a uma análise mais 
atenta, contudo, tal sistema se revela não menos hierárquico, rígido e padronizado que seu antecessor, com a notável (e negativa) diferença de que agora o elemento unificador é, diretamente, a pessoa do líder e, indiretamente, o poder subliminar dos meios de comunicação de massa e dos técnicos que os usam. Nesse meio-tempo, por outro lado, os partidos não desapareceram, mas se tornaram máquinas para a construção e a manutenção do poder do líder e dos agentes deste fora de qualquer controle por parte dos militantes e, cada vez mais facilmente e com frequência, da lei.

$\mathrm{Na}$ esteira de Manin, os defensores da democracia do público consideram que, com a transferência do poder do julgamento público das palavras para a visão, se considera possível tornar o "tribunal da opinião" efetivamente eficaz e aproveitar o melhor possível as potencialidades democráticas dos meios de informação e de comunicação, instrumentos capazes de restituir ao povo seu papel mais específico, que não é o de agir (uma massa, como escrevia Weber, não tem condições de agir sem um líder), mas o de olhar, observar e julgar. A democracia plebiscitária resulta em um divórcio interno à soberania popular, entre o povo como cidadãos participantes (com ideologias, interesses e a intenção de competir para obter a maioria) e o povo como uma unidade impessoal e completamente livre de interesses, que inspeciona e julga o jogo político jogado por alguns e dirigido por partidos eleitoralistas. $\mathrm{O}$ partidarismo não é expulso do domínio da decisão; é expulso do fórum, no qual o povo está ou atua como público ou massa indistinta e anônima de observadores que, como supremo espectador, "apenas olha" e julga, mas "não deseja ganhar" nada (Green, 2010, p. 29).

O preço para se tornar um líder nessa democracia plebiscitária deve tornar-se alto e custoso: esta é a única arma de controle que a audience possui. $\mathrm{O}$ custo que o líder deve pagar em troca do poder de que desfruta é a renúncia de grande parte de sua liberdade individual. O líder se coloca 
totalmente nas mãos do povo-audience porque está permanentemente sob os olhos deste. Este é "o obstáculo extra sobre as figuras públicas" que a democracia do público ou "ocular" exerce sobre quem tem o poder. Jeffrey Green, o autor dessa interpretação, propõe uma ideia interessante porque é inegável que aqueles que competem pelo poder devem ter consciência de que não possuem nem podem exigir a mesma amplitude de direito à privacidade de um cidadão comum. Mais poder implica mais responsabilidade e, portanto, menos liberdade de esconder e de se esconder. Por outro lado, quem exerce o poder político deseja ter o anel de Giges, ou seja, ser invisível para conseguir fazer aquilo que não poderia fazer impunemente em público sem sofrer reprimendas ou censuras ${ }^{10}$. O sigilo é um bem fundamental na vida privada dos indivíduos, mas pode ser um obstáculo intransponível no caso dos funcionários públicos e homens políticos. Sem dúvida, um ministro ou um 96 primeiro-ministro é protegido em seus direitos fundamentais como qualquer outro cidadão. No entanto, para que sua vida privada se mostre transparente e dentro da lei, é preciso haver algum tipo de inspeção. No caso dos políticos eleitos, ainda que não estejam sujeitos a nenhum mandato imperativo, a confiança não vem ex ante como um cheque em branco, mas implica e até exige ser corroborada pela evidência. Os órgãos de imprensa ou aquilo que se chama o poder negativo da opinião cumprem essa função de monitoramento. É inegável que competir por cargos públicos é uma escolha livre do candidato, o qual, quando a faz, deve levar em conta os ônus que daí derivam.

\footnotetext{
${ }^{10}$ Para uma válida reflexão sobre o sigilo e a opacidade como um bem importante das pessoas e os novos riscos que podem vir da obsessão com a transparência e das tecnologias que desejam saber e controlar tudo, ver Kateb (2004, pp. 93-113). Sobre a esfera na qual a publicidade é importante, ver Gutmann e Thompson (1996, pp. 95-127); sobre as promessas de publicidade no Estado democrático, ver Bobbio (1984, pp. 85-113).
} 


\section{A política da passividade}

Mas da convincente consideração acerca do "peso" da publicidade que o político eleito suporta e deve levar em conta não deriva a garantia de que levar o líder ao palco do teatro público comportará eo ipso tornar seu poder limitado e controlado; que em essência o público possa tomar o lugar da constituição e da norma da limitação do poder de maneira a tornar a política mais democrática por não estar sujeita a organismos não democráticos (como os tribunais) ou a cartas que, escritas por assembleias constituintes no passado, valem para limitar a vontade dos cidadãos atuais. A democracia plebiscitária, seja ela de massa ou da audience, tem como objetivo polêmico as instituições não democráticas ou de limitação da função democrática de legislar e tomar decisões. Mas "a motivação pela qual os políticos aceitam vestir uma máscara que seja aceitável socialmente não desaparece com o advento da democracia moderna" (Green, 2010, p. 29) e, portanto, o argumento dos plebiscitaristas que insiste no controle do poder do olhar popular - como controle superior até mesmo ao das normas constitucionais e, portanto, realmente democrático -, não é nem convincente nem provado. Baseia-se numa consideração abstrata sobre o papel do "público ocular" que as experiências concretas parecem contradizer.

O primeiro-ministro Silvio Berslusconi estava permanentemente sob o olhar dos meios de comunicação de massa que se intrometiam em sua vida não necessariamente para revelar seus potenciais delitos, mas para satisfazer a sede de escândalos a serem divulgados, algo que ao mesmo tempo criava o mercado dos escândalos e dava à opinião pública a forma de tabloide ${ }^{11}$. Colocar a vida do primeiro-

\footnotetext{
${ }^{11}$ Um estudo interessante sobre a política dos escândalos é Dirks (2006), no qual se afirma que os numerosos escândalos que preenchiam os jornais ingleses dos séculos XIX e XX serviram mais para sustentar a política imperial que para hostilizá-la. Ver em especial Dirks (2006, pp. 87-132).
} 
-ministro diante dos olhos do povo não servia para controlar ou para limitar seu poder; além disso, não tinha nem sequer um papel dissuasivo sobre suas escolhas ou preferências. O fato de Berlusconi possuir ou controlar seis canais de televisão nacionais certamente foi um fator agravante, mas não foi apenas este o motivo que tornou a democracia italiana da audience uma democracia passiva e bem pouco capaz de controlá-lo. De fato, até mesmo mais que a posse e o controle dos meios de informação, o império do poder ocular ou a inflação das imagens foi o fator que tornou o "olhar" particularmente incapaz de controlar. O paradoxo de insistir no fator estético da opinião pública à custa do cognitivo e do político-participativo é que não leva em conta o fato de que as imagens são a fonte de um tipo de julgamento que avalia mais gostos que fatos políticos e é, portanto, irremediavelmente subjetivo ${ }^{12}$.

O "gosto", explicou Immanuel Kant, exalta ao invés de 98 conter as potencialidades retóricas do mundo da visão e, além disso, isola o observador em vez de facilitar a comunicação com os outros observadores. De fato, enquanto é possível "falar de gosto", é impossível "discutir" sobre o motivo que leva uma pessoa a ter aquele gosto, à medida que o gosto está além da contestação e da razão deliberativa por ser uma expressão pessoal que não tem parâmetros de medida fora do sentir do sujeito. O máximo que se pode fazer é ter fé que "se possa chegar a um acordo mútuo" sobre determinado gosto e agir para tornar isso possível (com a arma da persuasão retórica, por exemplo). Mas o gosto é e continua a ser subjetivo e dificilmente pode ser veículo para uma partilha ou mesmo para um acordo entre observadores. Ao contrário, é o raciocínio hipotético (a "imaginação", de acordo com Kant) que tem o poder e a capacidade de estimular e animar a vontade dos sujeitos

\footnotetext{
${ }^{12}$ Sobre as três funções do "público", ver Eder (2008).
} 
e o faz direcionando as nossas razões para a formação de estratégias que possam levar ao consenso:

[...] devemos ter a esperança de chegar a um acordo mútuo; pode-se contar com condições para um juízo que não tenham uma validade meramente privada e não sejam meramente subjetivas, o que é completamente oposto ao princípio fundamental de que cada um tem os seus próprios gostos (Kant, 2008, p. 1092) ${ }^{13}$.

A ideologia é filha do raciocínio hipotético e da imaginação; leva-nos a preconizar o futuro de modo a mobilizar a nossa vontade e a vontade dos outros no presente para tentar realizá-lo. A ideologia é um comportamento racional em um campo que, como o político, tem a ver com o futuro ou com decisões que fazem com que aconteçam coisas. O "afeto", condenado por Kant na esfera do conhecimento, é objeto de uma consideração mais benévola por parte do próprio Kant quando se refere "àquilo que é ideal e até puramente moral". "Esta disposição moral não pode deixar de visar a uma constituição republicana": de resto, com quais "instrumentos" se pode passar de uma ordem despótica para uma ordem republicana se não se leva em conta o crescimento de uma espécie de crença coletiva em algo de bom e de possível, tão forte a ponto de levar a superar o senso do perigo e o cálculo da conveniência? ${ }^{14}$

Qual é então o resultado das imagens visuais e do gosto? "O resultado é este: que a prioridade da televisão são os scoop e o rating (a audience mais ampla possível)" (Sartori,

\footnotetext{
${ }^{13}$ A esse respeito, ver também Steinberger (1993, pp. 153-38) e Longuenesse (1993, p. 6).

${ }^{14}$ Tal raciocínio guiou a análise crítica feita por Hirschman (1982) da convicção liberal clássica de acordo com a qual a "felicidade", para os modernos, só pode ser associada a, ou estimulada pela, dimensão privada da vida e pelos interesses econômicos em particular.
} 
1997, p. 149). É previsível, portanto, que a informação, por si só, não dá mais poder ou não confere mais poder à faculdade de julgar. Ao contrário, a hegemonia do olhar levaria o público exatamente na direção oposta à prevista pelos defensores do plebiscitarismo da audience. A audience não controla o líder, mas sugere ao líder e a seus técnicos da imagem aquilo que ele deveria fazer para obter o favor do povo e, se necessário, resguardar da visão aquilo que o povo não quer ver. Além disso, o império da visão inevitavelmente desgasta o teor do estilo do discurso político. A experiência italiana confirma esse diagnóstico porque nos anos em que Berlusconi reinou como líder plebiscitário com uma política da audience, as questões centrais do diálogo eram sugeridas pela lógica do marketing ou pela publicidade de venda. Enquanto isso, os temas e problemas políticos haviam sido eliminados do discurso público que os meios de comunicação de massa governavam porque não eram atraentes, nem 100 para as organizações televisivas, nem para os espectadores ${ }^{15}$. O paradoxo do público-olhar-total, ou seja, da ideia de que a audience consiste em um eficaz impedimento extra ao poder do líder justamente por sua exigência de transparência, é que as decisões políticas continuam a ser não vistas ou não reveladas porque pertencem a objetos que geralmente são menos atraentes aos gostos estéticos dos espectadores e a seu desejo de espetacularidade. Conhecer muito pouco do que os políticos eleitos fazem quando governam é o preço que os cidadãos italianos pagaram ao se tornar um olhar que queria ver tudo e era alimentado por um tipo de informação que era guiada pelo objetivo de impressionar a mente da audience com imagens que provocavam compai-

\footnotetext{
${ }^{15}$ Comentando sobre as relações extraconjugais do presidente Clinton que ocuparam a imprensa norte-americana por metade de seu segundo mandato, Gutmann e Thompson (1996, p. 124) afirmam com razão que a qualidade da deliberação naqueles anos teria sido melhor se a opinião pública estivesse menos interessada nos fatos privados e morais que nos políticos.
} 
xão, raiva, simpatia ou inveja etc. Produzir efeito emotivo, escreveu Niklas Luhmann, é a função dos meios de comunicação de massa, os quais, portanto, reproduzem a não transparência precisamente quando alardeiam a transparência e o conhecimento total (2000, p. 103). Tornar a vida do líder visível e um objeto de espetáculo permanente pode gerar opacidade com a pretensão da publicidade.

O caso italiano parece provar - contra quem acredita que a democracia plebiscitária da audience está mais próxima da democracia do que, por meio dos partidos e das eleições, está a democracia representativa - que a transformação da base da política dos partidos-organização, o programa dos partidos líquidos e as sondagens tornaram o povo não apenas menos capaz de controle e menos no controle, mas, para todos os efeitos, incapaz de controlar, enquanto tornaram o domínio da política mais vulnerável ao sigilo, à opacidade e à corrupção.

Há alguns anos, Alessandro Pizzorno interpretou o paradoxo contido nessa transformação midiática da política como um sinal do declínio da linguagem e do juízo político e sua substituição pela linguagem e pelo juízo da moralidade subjetiva ou ditada pelo gosto. A centralidade dos símbolos sobre os programas, da pessoa do líder sobre o coletivo do partido-organização, se traduz na centralidade das qualidades morais sobre as políticas na formulação que os cidadãos fazem de seus juízos políticos. As virtudes políticas (prudência, competência etc.) declinam enquanto as morais (estéticas, sexuais etc.) se tornam centrais. Um resultado comprovado dessa transformação é, de acordo com Pizzorno, o aumento da corrupção, porque o que deveria ser um objeto de visibilidade não é interessante, nem para a audience, nem para os técnicos dos meios de comunicação, nem, obviamente, para os especialistas que cuidam da imagem pública do líder. A política se torna mais profissional no sentido de que se torna uma atividade que vive de trocas 
privadas e ocultas, embora menos atenta ao interesse dos cidadãos e, nesse sentido, menos politicamente competente. Por fim, o plebiscito da audience facilita a corrupção justamente quando pretende transformar o povo em um grande olho (Pizzorno, 1998, pp. 45-63).

Neste ponto, posso concluir a reflexão sobre o modelo de democracia plebiscitária da audience comparando-o com os dois outros modelos que se consolidaram nos anos da democracia por meio dos partidos, o deliberativo (racionalista e normativo) e o processualista (realista e instrumental), o primeiro associado ao nome de Jürgen Habermas e o segundo ao nome di Joseph A. Schumpeter. Os argumentos que os deliberativistas e os processualistas apresentaram são essencialmente éticos e morais, feitos ou em nome 102 do princípio de universalidade dos argumentos racionais como princípio legitimador, ou em nome dos princípios de agregação das preferências e troca periódica dos eleitos como as únicas vias pragmáticas para resolver a carência de racionalidade contida nas opiniões políticas sem renunciar à liberdade, ou melhor, ao consenso eleitoral. Os teóricos habermasiamos e os schumpeterianos concebem a democracia como uma ordem política baseada na autonomia e no voto, uma visão da atividade política centrada na decisão e na voz. Eles tratam a opinião do indivíduo privado como uma realidade que não deveria entrar no domínio político sem sofrer transformações. Os habermasianos propõem a obtenção disso pela filtragem das opiniões privadas por meio da deliberação racional e pública (usando a gramática dos direitos e da lei, não a das crenças ou das conveniências pessoais); os schumpeterianos, pela extração das opiniões privadas a unidade numérica de cálculo, o fato mensurável do voto (um dado que a contagem tor- 
na incontestável e isenta das interpretações pessoais). Essas duas estratégicas são o que a democracia plebiscitária da audience contesta e refuta quando opõe à intermediação do juízo reflexivo (por meio das razões públicas ou dos partidos) o juízo reativo e emotivo às imagens.

Posso agora voltar ao diagnóstico de Manin de acordo com o qual está em andamento uma transformação da democracia dos partidos na democracia plebiscitária, na qual o aparecer em público define a arte da política do público ou da audience. Ao sublinhar a passagem da participação à espectatorialidade, Manin esclarecia que consenso e discussão são ambos essenciais para a legitimidade democrática, enquanto o juízo não é, por si só, a marca do autogoverno. Por esse motivo, avaliava a transição da democracia por meio dos partidos políticos para a democracia da audience como um sinal contraditório porque, enquanto livra os eleitores da interpretação dos partidos, diminui o poder deles sobre o líder político. Quando os cidadãos votavam por partidos com plataformas e programas, exerciam seu juízo sobre a política futura, o voto deles não expressava simplesmente a confiança na pessoa do notável, como acontecia no século XIX quando o candidato-notável era o representante (ou como acontece agora com os partidos do líder). Na democracia por meio dos partidos, a imagem do candidato não tomava o lugar das expectativas futuras dos eleitores como acontece na democracia plebiscitária, em que as eleições estão centradas na imagem do candidato e a referência aos programas e às plataformas políticas é quase irrelevante. A consequência é que mesmo a accountability (a correspondência dos eleitos aos eleitores) vem a perder relevância porque os eleitores não têm mais nenhum controle, mesmo que indireto, sobre as questões públicas e as políticas, nem sequer durante as campanhas eleitorais. Claramente, Manin julga a transformação do discutir e do debater (e votar nos programas) no olhar e no julgar ocu- 
pando uma posição de espectador como um sinal de mal-estar (malaise), não como uma melhoria. De fato, conclui o livro com estas palavras desalentadoras que faço minhas: "O governo representativo parece ter encerrado seus progressos para o autogoverno popular".

\section{Nadia Urbinati}

é professora do departamento de ciência política da Universidade de Columbia.

\section{Referências bibliográficas}

BOBBIO, N. 1984. Il futuro della democrazia, Turim: Einaudi.

CALISE, M. 2010. Il partito personale: i due corpi del leader. Roma/Bari: Laterza.

CAVALLI, L. 1981. Il capo carismatico, Bolonha, Il Mulino.

DIRKS, N. 2006. Scandal of empire: India and the creation of imperial Britain. Cambridge, MA/London: Belknap Press of HUP.

EDER, K. 2008. "The transformations of the public sphere and their impact 104 on democratization”. Annali della Fondazione Giangiacomo Feltrinelli, ano XLIII, pp. 247-79.

FABBRINI, S. 1998. Il principe democratico: la leadership nelle democrazie contemporanee. Roma/Bari: Laterza.

FREEDEN, M. 1996. Ideologies and political theories: a conceptual approach. Oxford: OUP.

GREEN, J. E. 2010. The eyes of the people: democracy in the age of spectatorship. Oxford/New York: OUP.

GUTMANN, A.; THOMPSON, D. F. 1996. Democracy and disagreement. Cambridge, MA/London: The Belknap Press of HUP.

HIRSCHMAN, A. O. 1982. Shifting involvements: private interest and public action. Princeton, NJ: PUP.

KANT, I. 2008. Critica del giudizio. Milano: Mondadori (Meridiani).

KATEB, G. 2004. Patriotism and other mistakes. New York/London: YUP.

KISHLANSKY, M. A. 1986. Parliamentary selection: social and political choice in early modern England. Cambridge: CUP.

LONGUENESSE, B. 1993. Kant et le pouvoir de juger: sensibilité et discursivité dans l'Analytique transcendentale de la Critique de la raison pure. Paris: PUF.

LUHMANN, N. 2000. The reality of the mass media. Stanford: Stanford University Press. 
MAIR, P. 1994. "Party organization: from civil society to the state". In: KATZ, R. S.; MAIR, P. (eds.). How parties organize: changes and adaptation in party organizations in western democracy. London: Sage, pp.1-22.

MANIN, B. 1997. The principles of representative government. Cambridge: CUP. PIZZORNO, A. 1998. Il potere dei giudici: stato democratico e controllo della virtù. Bari/Roma: Laterza.

POGUNTKE, T.; WEBB, P. D. (eds.). 2005. The presidentialization of politics: a comparative study of modern democracies. Oxford: OUP.

POSNER, E. A.; VERMEULE, A. 2011. The executive unbound: after the Madisonian republic. Oxford: OUP.

ROSANVALLON, P. 2006. La contre-démocratie : la politique à l'âge de la défiance. Paris: Seuil.

SARTORI, G. 1997. Comparative constitutional engineering: an inquiry into structures, incentives and outcomes. New York: New York University Press.

STEINBERGER, P. J. 1993. The concept of political judgment. Chicago/London: The University of Chicago Press.

URBINATI, N. 2006. Representative democracy: principles and genealogy. Chicago/London: The University of Chicago Press.

. 2010. "Unpolitical democracy". Political Theory, v. 38, fasc. 1, pp. $65-92$. 


\section{DA DEMOCRACIA DOS PARTIDOS AO PLEBISCITO DA AUDIENCE}

NADIA URBINATI

Resumo: O presente artigo visa analisar as principais transformações e tendências das democracias contemporâneas. As mudanças realizadas assumiram formas semelhantes na maioria das democracias existentes. Os fenômenos mais recorrentes advindos delas foram o declínio dos partidos organizacionais e programáticos, especialmente no caso europeu e, como consequência disto, a emergência dos "partidos leves", o que resultou, como tendência geral, na perda e na crença da qualidade da política representativa. Emerge dessa configuração, a democracia de público atravessada por todos os lados pelo plebiscitarianismo. A grande importância adquirida pelos grandes meios de comunicação e seu controle monopólico reforçam a dimensão plebiscitária da democracia de audience. O efeito mais antidemocrático disto reside no fato que os eleitores perdem a possibilidade de formar juízos críticos, porque transformados muito mais em espectadores - que mais olham do que agem -, o que torna a política muito mais vulnerável ao sigilo e à opacidade, e a democracia menos democrática.

Palavras-chave: Democracia de Público; Declínio dos Partidos Programáticos; Partidos Leves; Crise da Linguagem e do Juízo Político; Crise da Representação Democrática.

\section{FROM THE PARTIES'S DEMOCRACY TO THE AUDIENCE'S REFERENDUM}

Abstract: This article aims to analyze the main transformations and trends of contemporary democracies. The accomplished changes have taken similar forms in the majority of existing democracies. The most recurrent phenomena arising from them were the decline of organizational and programmatic parties, especially in the 
case of Europe, and as a consequence, the emergence of "soft parties", which resulted, as general trend, and the belief in the loss of quality of policy representative. Emerges from this setting, the public democracy traversed everywhere by plebiscitarianism. The importance acquired by the mainstream media and its monopolistic control enhances the plebiscitary dimension of the audience's democracy. The most undemocratic effect of it lies in the fact that electors lose their ability to form critical judgments, because they are transformed in spectators - that more look on than act - which makes the politics much more vulnerable to secrecy and opacity, and democracy less democratic.

Keywords: Public Democracy; Decline of Programmatic Parties; Soft Parties; Crisis of Political Language and Judgment; Crisis of Democratic Representation. 